University of Nebraska - Lincoln

DigitalCommons@University of Nebraska - Lincoln

$6-2020$

Colorantes presentes en mochilas Ika de la colección etnográfica del Världskulturmuseet (Antiguo Museo Etnografico) en Gotemburgo, Suecia, realizada por Gustav Bolinder

Beatriz Devia

Marianne Cardale de Schrimpff

Follow this and additional works at: https://digitalcommons.unl.edu/pctviii

Part of the Art and Materials Conservation Commons, Fiber, Textile, and Weaving Arts Commons, Indigenous Studies Commons, Latin American Languages and Societies Commons, Museum Studies Commons, and the Other History of Art, Architecture, and Archaeology Commons

This Article is brought to you for free and open access by the Centre for Textile Research at DigitalCommons@University of Nebraska - Lincoln. It has been accepted for inclusion in PreColumbian Textile Conference VIII / Jornadas de Textiles PreColombinos VIII (2019) by an authorized administrator of DigitalCommons@University of Nebraska - Lincoln. 


\title{
Colorantes presentes en mochilas Ika de la colección etnográfica del Världskulturmuseet (Antiguo Museo Etnografico) en Gotemburgo, Suecia, realizada por Gustav Bolinder
}

\author{
Beatriz Devia* \& Marianne Cardale de Schrimpff ${ }^{\dagger}$ \\ * Universidad Distrital Francisco José de Caldas, Bogotá, Colombia, bodeviac@udistrital.edu.co \\ † Fundación Procalima, marianne@procalima.org
}

\begin{abstract}
Resumen
El etnólogo sueco, Gustav Bolinder en los años 1914-1921 realizó una colección extensa de objetos elaborados por grupos indígenas del norte de Colombia, incluyendo a los Ika y otras etnias de la Sierra Nevada de Santa Marta. La colección incluye numerosas mochilas Ika. Estas son en fique, algodón y lana, para diferentes usos. Tanto los motivos de los diseños como los colorantes y las fibras utilizadas expresan cierto grado de sincretismo. Aunque la mayoría de los diseños son tradicionales, se observa algunos animales domésticos y la cruz, al parecer resultado de la influencia de la misión de padres capuchinos establecida en ese tiempo en la región.

El análisis de los colorantes presentes en mochilas de esta colección, proporcionó indicios sobre el empleo de especies de palo brasil (posiblemente Haematoxylum brassileto), Picramnia gracilis, Berberis meollacensis y Fridericia chica (Sin. Arrabidaea chica). Adicionalmente se encuentran otras moléculas sin identificar que posiblemente correspondan al empleo de colorantes sintéticos. Los resultados comparados con recientes estudios de colorantes de uso tradicional por la comunidad Ika, muestran una continuidad de más de cien años en el uso de especies tintóreas de la región y guardan una estrecha relación con los colorantes determinados en textiles prehispánicos del norte de la cordillera Oriental en Colombia.
\end{abstract}

Palabras claves: Análisis químico, Bolinder, Bignoniaceae, Picramniaceae, Berberidaceae, muestras etnográficas.

\begin{abstract}
During the years 1914-1941, the Swedish ethnographer, Gustav Bolinder, collected an extensive range of ítems from several Amerindian societies in northern Colombia, including the Ika and other indigenous groups of the Sierra Nevada de Santa Marta. The collection includes a large number of Ika bags (known as mochilas) made from agave fibre, cotton or wool and used for different purposes. Both the design motifs and the dyes and fibres employed reveal a certain degree of syncretism. Although the majority of the designs are traditional, some of the bags include domestic animals and the cross, possibly as a result of the influence of the Catholic mission founded by Capuchin monks in the region at this time. The analysis of the colorants in the mochilas from this collection indicates the use of species of brasil wood (possibly Haematoxylum brassileto), Picramnia gracilis, Berberis meollacensis y Fridericia chica (Sin. Arrabidaea chica). In addition, some unidentified molecules may be from synthetic colorants. When these results are compared with recent studies of the colorants still used traditionally by the Ika community, they demonstrate continuity in the use of certain dye plants from the region during a period of
\end{abstract}

DOI: $10.32873 /$ unl.dc.zea.1217

Published in PreColumbian Textile Conference VIII / Jornadas de Textiles PreColombinos VIII, ed. Lena Bjerregaard and Ann Peters

(Lincoln, NE: Zea Books, 2020). https://digitalcommons.unl.edu/zeabook/ 
more than a hundred years. At the same time, they reveal a close relationship with the colorants identified on prehispanic textiles from the northern region of the Eastern Cordillera in Colombia.

Key words: chemical analysis, Bolinder, Bignoniaceae, Picramniaceae, Berberidaceae, ethnographic samples.

\section{Résumé}

Dans les années 1914-1921, l'ethnologue suédois Gustav Bolinder a réalisé une vaste collection d'objets élaborés par des groupes indigènes du nord de la Colombie, incluant les Ika et d'autres ethnies de la Sierra Nevada de Santa Marta. La collection comprend de nombreux sacs Ika. Ces derniers sont en fique, coton et laine pour différents usages. Tant les motifs que les colorants et les fibres utilisés, expriment un certain degré de syncrétisme. Bien que la majorité des figures soient traditionnelles, on observe quelques animaux domestiques et une croix, probablement résultat de l'influence de la mission catholique fondée par les pères Capucins établie à cette période dans la région.

L'analyse des colorants présents dans les sacs de cette collection a fourni des indices sur l'emploi des espèces du palo brasil (possiblement Haematoxylum brassileto), Picramnia gracilis, Berberis meollacensis et Fridericia chica (Sin. Arrabidaea chica). De plus, ont été découvert d'autres molécules non identifiées qui probablement correspondent à l'emploi de colorants synthétiques. Les résultats sont comparés à de récentes études de colorants d'usage traditionnel par la communauté Ika, ils montrent une continuité dans l'usage des espèces tinctoriales de la région. En même temps, ils gardent une étroite relation avec les colorants identifiés dans les tissus préhispaniques du nord de la cordillère orientale en Colombie.

Mots-clés: Analyse chimique, Bolinder, Bignoniaceae, Picramniaceae, Berberidaceae, échantillons ethnographiques.

\section{Introducción}

Este trabajo se inició en la etapa final de la investigación "Contribución al conocimiento de las fuentes de colorantes precolombinos a partir del estudio de las especies colorantes de uso tradicional por la comunidad indígena Ika de Nabusímake, Sierra Nevada de Santa Marta, Colombia” financiado por la Fundación de Investigaciones Arqueológicas Nacionales (FIAN) y por la Universidad Distrital Francisco José de Caldas, Colombia.

Diferentes colecciones etnográficas se han realizado en torno a la cultura material de los grupos indígenas habitantes de la parte norte del territorio colombiano, como en el Museo Americano de Historia Natural en New York (USA), en el Museo de las Culturas del Mundo en Gotemburgo (Suecia), en el Museo Quai Branly en Paris (Francia) y el museo etnológico en Berlín (Alemania). Pero tal vez la más completa en torno a los materiales perteneciente a los indígenas Ika de la Sierra Nevada de Santa Marta es la realizada por el antropólogo Gustav Bolinder, para el entonces museo etnográfico de Gotemburgo, entre 1914 y 1924.

Para la investigación que se venimos desarrollando en torno a los colorantes presentes en textiles arqueológicos colombianos y sobre las especies promisorias de estos colorantes, es de gran importancia la información guardada en los materiales etnográficos. De ahí el gran valor que tiene poder contrastar la información adquirida por el trabajo realizado hace cinco años con la comunidad Ika de Nabusimake sobre especies colorantes de uso tradicional, con la información recopilada por Gustav Bolinder, 100 años atrás en la misma comunidad.
Con este trabajo se busca implementar el conocimiento sobre las propiedades y aplicaciones de las especies tintóreas de la región. Aportar evidencias experimentales sobre el uso de los materiales y técnicas ancestrales de tintorería, a la vez que resaltar el valor de este conocimiento en la comunidad Ika.

\section{Colorantes utilizados por la comunidad Ika de Nabusi- make, Sierra Nevada de Santa Marta.}

Los Ika junto con los Kogi, Wiwa y Kankuama habitan la Sierra Nevada de Santa, localizada entre los departamentos del Magdalena, Córdoba y Cesar (Figura 1). Pertenecen a la familia liguistica Chibcha (Uribe, 1990). Su territorio comprende diferentes pisos térmicos entre 1200 hasta 5600 msnm, con un ecosistema montañoso, seco y en algunas partes desértico, de coberturas naturales y alteradas. La población es de 14.799 individuos según el Departamento Nacional de Planeación de Colombia (DNP).

El trabajo de campo se realizó con la comunidad Ika de Nabusimake, en las veredas Sirkairo y el Pantano, municipio de Pueblo Bello. Especialmente con la asociación de mujeres Akitinkuchua, empeñadas en el rescate de la tintoreria tradicional y encargadas de la comercialización de diferentes productos, entre estos la venta de las mochilas que producen las mujeres de la comunidad. En la actualidad, las mochilas de mayor comercialización son las tejidas en fibras de lana con diseños tradicionales logrados con los colores naturales de la lana y en menor escala, las elaboradas con fibras de fique o maguey (Furcraea bedinghausii) teñidas con colorantes naturales. Debido a la poca disponibilidad 


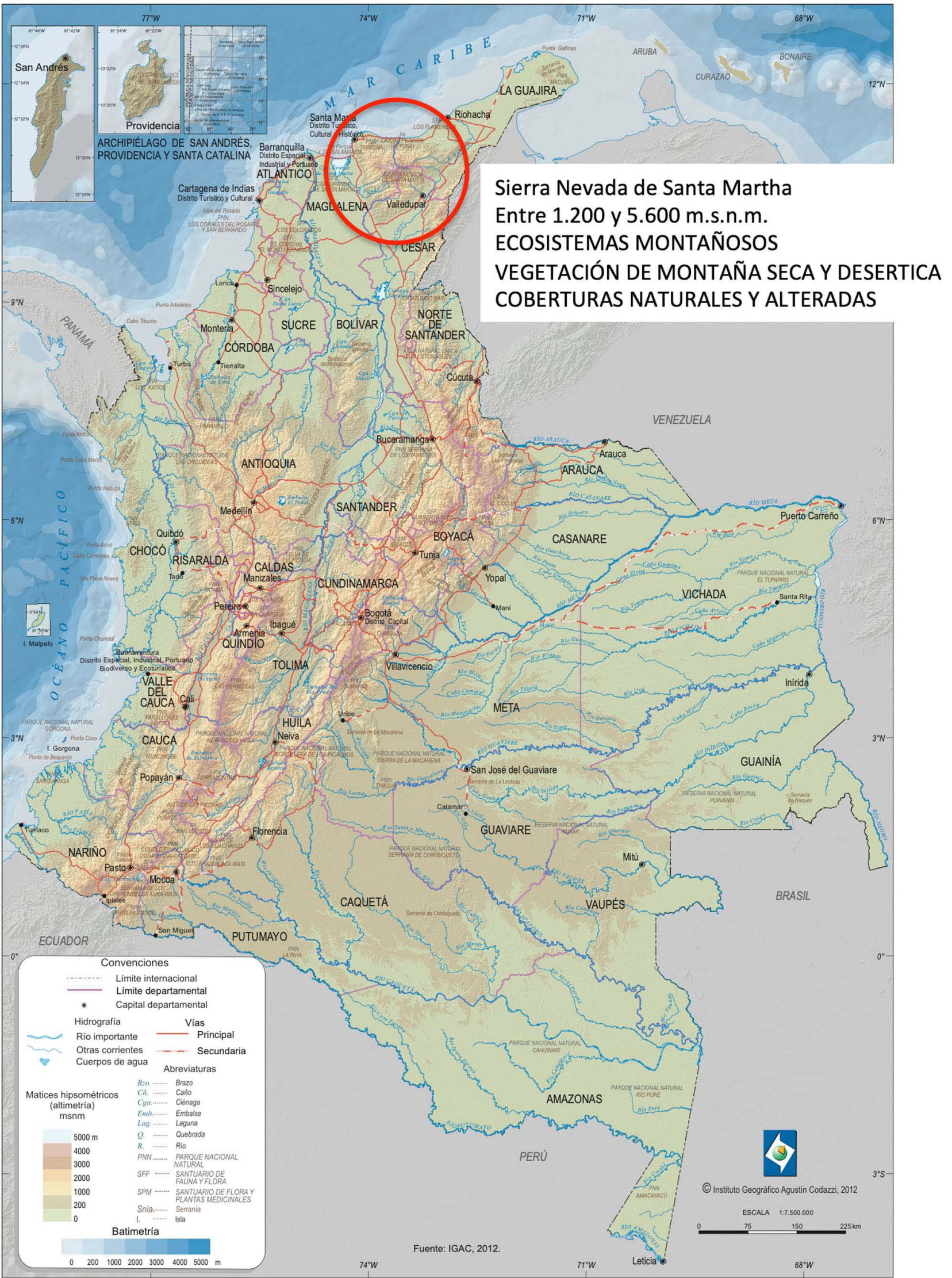

Figura 1. Localización de la Sierra nevada de Santa Marta, lugar donde habitan las comunidades indígenas Ika, Kogi, Wiwa y Kankuama. 


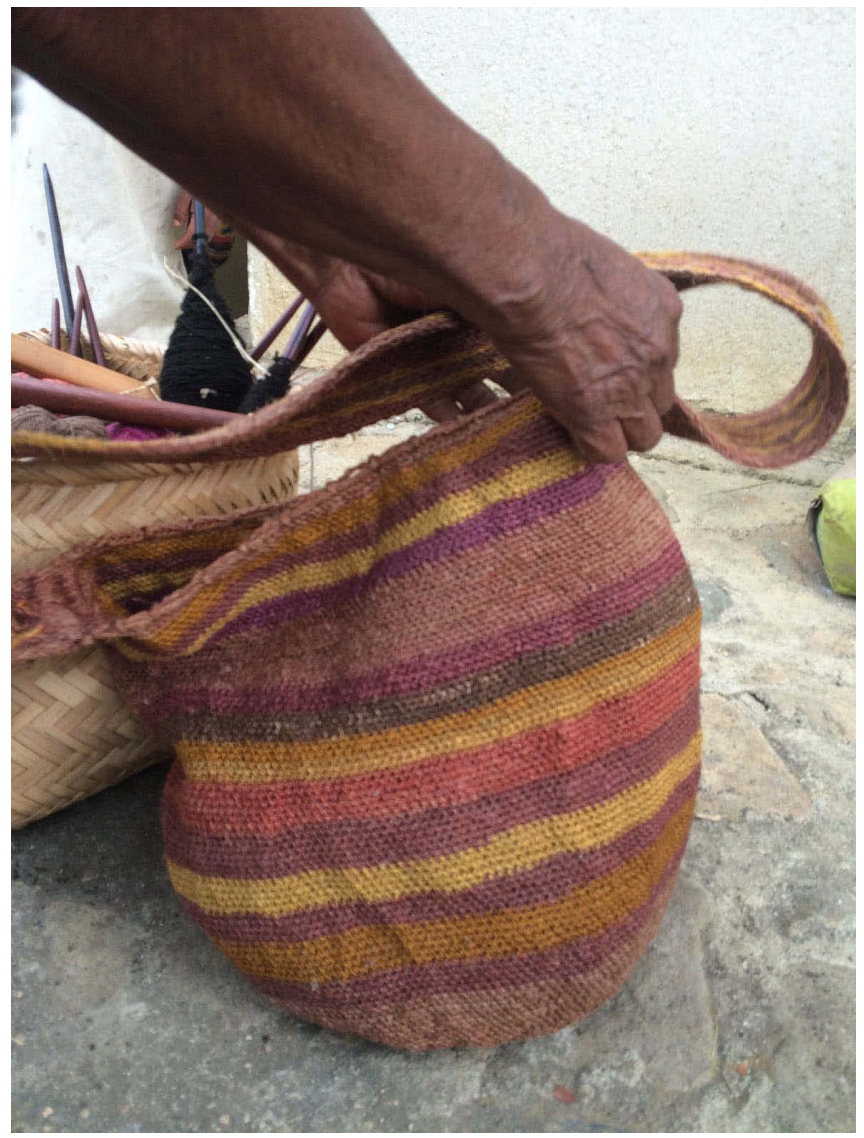

Figura 2. Mochila Ika actual, fibras de fique teñidas con Kugwinu (Weinmannia pinnata), Uru (Picramnia gracilis), Chunnu (Berberis meollacensis) Sorkuanu (Bocconia frutescens), y palo brasil (Haematoxylum brasiletto), hecha por la señora Ester Izquierdo de Nabusimake, fotografía de Marianne Cardale de Schrimpff.

de algodón se producen muy pocas mochilas con esta fibra. En el teñido del fique se conserva el conocimiento del teñido con plantas (Figura 2). Las plantas tintóreas y los colores que se obtienen tienen un alto significado en la cosmología de los Ika (Reichel-Dolmatoff, 1949-1950). El proceso de teñir y los individuos que participan en él están regidos por normas de la comunidad. Las fibras teñidas sobre algodón se utilizan para obtener ofrendas rituales (pagamentos) (Giraldo Jaramillo, 2014).

\section{Especies colorantes de uso actual.}

Trabajos anteriores realizados por Marianne Cardale de Schrimpff (Cardale de Schrimpff, 1972), Camilo Niño Izquierdo (Niño Izquierdo, 2011) y Beatriz Devia (Devia et al., 2016) permitieron identificar un grupo de dieciocho especies, entre las plantas tintóreas utilizadas en la actualidad por la comunidad como fuentes de colorantes, para la

\begin{tabular}{|c|c|c|c|c|c|c|}
\hline NOMBPE CIENTIEICO & & & \\
\hline NOMBRE CIENTIFICO & IKA & COLOR & ARBOL & ARBUSTO & LIANA & HIERBA \\
\hline Berberis meollacenses & Chunnu & & & & & \\
\hline Bocconia frutescens & Sorkwant & & & & & \\
\hline Curcuma longa & Batatilla & & & & & \\
\hline Chaetolepis alpina & Uchaba & & & & & \\
\hline Clusia multiflora & Gronu & & & & & \\
\hline Maclura tinctorea & Morita & & & & & \\
\hline Vismia baccifera & Mumkwinu & & & & & \\
\hline Bixa orellana & Achote & & & & & \\
\hline Weinmannia pinnata & Kugwinu & & & & & \\
\hline Fridericia chica & Sisita & & & & & \\
\hline Haematoxylum brasiletto & Barrasin & & & & & \\
\hline Escallonia paniculata & Manuzitinu & & & & & \\
\hline Galium hypocarpium & Kasira & & & & & \\
\hline Picramia gracilis & Uru & & & & & \\
\hline Mucuna sp. & Sikura & & & & & \\
\hline Piper aduncum & Gungunu & & & & & \\
\hline Senna pendula & Jumisai & & & & & \\
\hline Myrsine coriacea & Yeganu & & & & & \\
\hline Mucuna sp. & Sikura & & & & & \\
\hline Myrsine coriacea & Yeganu & & & & & \\
\hline Picramia gracilis & Uru & & & & & \\
\hline
\end{tabular}

Tabla 1. Especies tintóreas empleadas en la comunidad Ika

obtención de tonos que van desde el amarillo hasta el púrpura, ver Tabla (1) . Este grupo está formado por especies nativas con excepción de la Curcuma longa L. (Batatilla) especie introducida de origen indico-malayo, utilizada principalmente como aditivo colorante para alimentos y especia (Freire González y Vistel Vigo 2015). De acuerdo a su porte hay árboles como Haematoxylum brasiletto y Maclura tinctórea, característicos del bosque tropical seco; Bocconia frutescens y Picramnia gracilis comunes en el bosque andino, arbustos como Berberis meollacensis, característico del ecosistema de la sierra nevada, hierbas como el Galium hypocarpium comunes en el bosque andino $y$ lianas como Fridericia chica de la selva tropical húmeda.

Entre los tonos obtenidos prevalecen los amarillo y naranja, seguidos de los rojizo, verde y por último purpúra. No se observa el empleo de fuentes para la obtención del azul. Los colorantes se obtienen de diferente parte de la planta dependiendo de la especie: para los colores amarillo y anarajado se utiliza la raiz de Berberis meollacensis L.A. Camargo (Chunnu), los rizomas de Curcuma longa, la madera de Bocconia frutescens L.(Sorkwuanu) y Maclura tinctórea L. (Morita), los frutos en Vismia baccifera (L.) Triana \& Planch (Mumkwinu) y Clusia multiflora Kunth, las semillas en Bixa orellana L. y la planta entera en Chaetolepis alpina L. La madera de Weinmannia pinnata L. (Kugwinu), para tonos café rojizo, para el rojo madera de Escallonia paniculata (Ruiz \& Pav.) Roem. \& Schult (Manuzitinu) y Haematoxylum brasiletto Karst ( Barracin), para el rojo y anaranjado hojas de Fridericia chica (Bonpl.) L.G. Lohmann (Sisita) y raíz de Galium hypocarpium. L. (Kasira). Para el verde la planta 

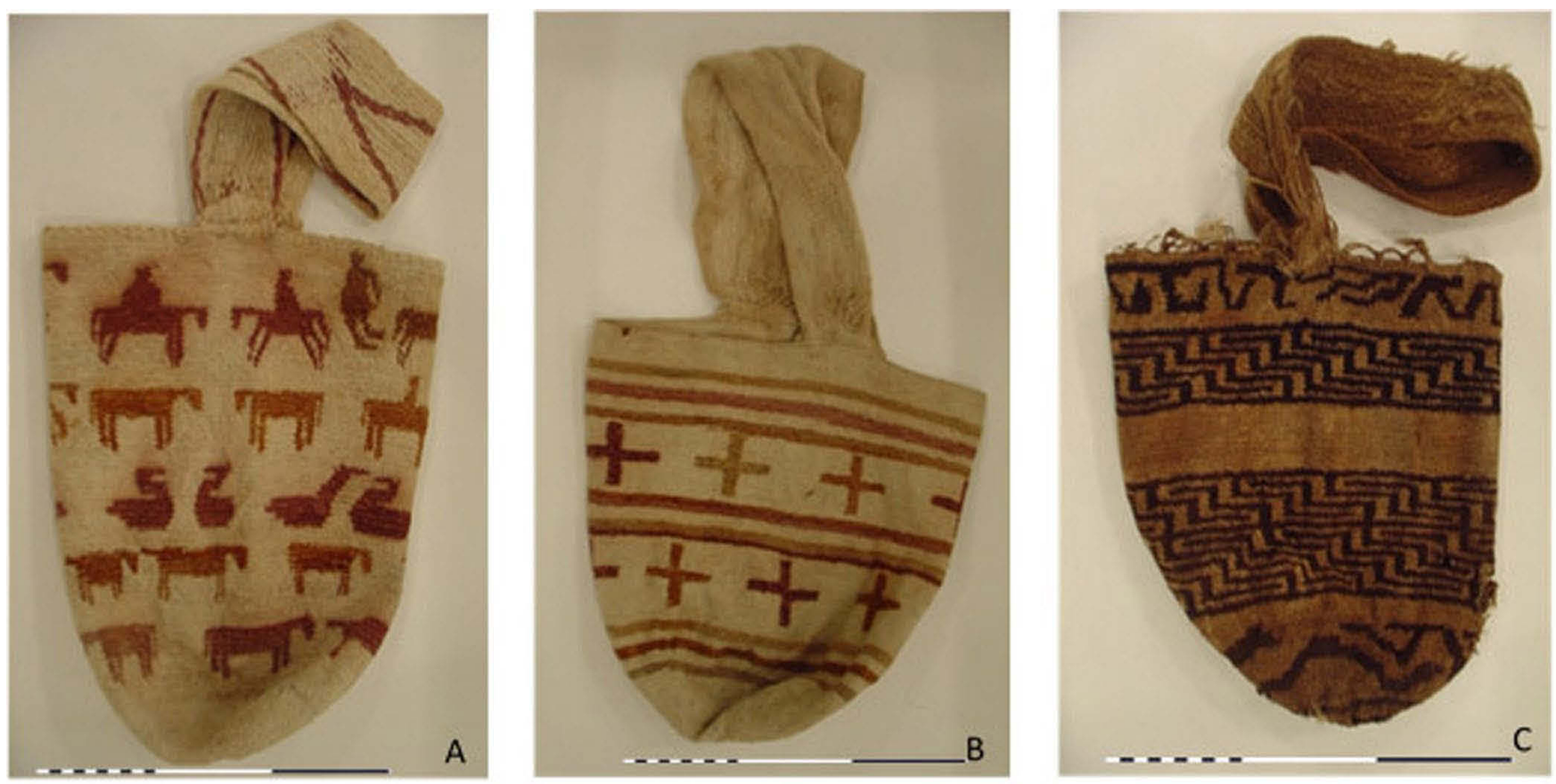

Figura 3. Mochilas Ika, Världskulturmuseet, Gotemburgo, Suecia, A) 1916.03.435 y B) 1916.03.786 poseen motivos diferentes a los tradicionales en los diseños Ika. En la mochila C) 1916.03.425 se conservan los diseños tradicionales.

entera de Mucuna sp. ${ }^{1}$ (Sikara), Senna pendula Willd (Jumisai) y Piper aduncun L.(Gungunu). Con los frutos de Myrsine coriaceae Sw.(Yeganu), se puede obtener grís y violeta, con la Sikara también se puede obtener gris oscuro casi negro. Y, con las hojas frescas de Picramnia gracilis Tul. (Uru) púrpura y violeta.

Algunas de las plantas tintóreas se cultivan para uso alimenticio como Bixa orellana y Curcuma longa, otras como Fridericia chica como especie medicinal y tintórea, con $\mathrm{Pi}$ cramnia gracilis de difícil domesticación, en algunos casos se ha logrado su cultivo para fines tintóreos. Otras como Haematoxylum brasiletto y Maclura tinctórea a pesar de ser conocidas como especies tintóreas (Patiño 1975-1976), ya no se cultivan y se usan especialmente como especies madereras. Las otras se emplean de acuerdo a la disponibilidad. Del grupo de especies registradas en la tabla 1, se destaca por la frecuencia en su empleo ${ }^{2}$ Picramnia gracilis (Uru).

\section{Materiales etnográficos relacionados con el uso de los colorantes en la colección etnográfica del Världskulturmuseet en Gotemburgo, Suecia.}

En sus temporadas en Colombia desde 1913, Gustav Bolinder hizo colecciones de textiles y otros materiales, entre estos los relacionados con la tintorería, de casi todos los grupos indígenas del norte de Colombia. En la Sierra Nevada de Santa Marta la mayor parte de su colección viene de Nabusimake, en aquella época llamado San Sebastián de Rabago, donde una comunidad de monjes capuchinos había establecido una misión (Bolinder 1925). Aunque hay un buen número de mochilas elaboradas en algodón y en fique, también hay varias en lana. Al parecer, no hay datos en cuanto a cuando se empezó a utilizar esta última fibra para las mochilas, pero parece posible que su uso fue fomentado por la misión. Los monjes establecieron un gran internado donde funcionaba una escuela para los niños indígenas. Las niñas seguramente seguían tejiendo sus mochilas y algunos de los motivos como animales y posiblemente, la cruz, parecen ser el resultado de la influencia de la misión (Figura 3). Sin embargo, se encuentran también otros diseños, por los menos algunos de los cuales como el "pensamiento de la mujer" que todavía forma parte del archivo tradicional (Aroca 2009).

Entre los materiales etnográficos relacionados con el uso de los colorantes, por la comunidad Ika, en la colección de Gustav Bolinder se encuentra: mochilas, prendas de vestir, muestras de fibras teñidas y de plantas tintóreas. Entre las mochilas, de acuerdo a las fibras empleadas en su elaboración, se encuentran dieciocho en algodón; diecisiete en fique

1. En la Sierra Nevada hay registros de Mucuna mutisiana, cerca al rio Donachui, información tomada de la base de datos del herbario nacional colombiano

2. Información obtenida en el trabajo de campo realizado entre el 2013 y 2015 en Nabusimake 

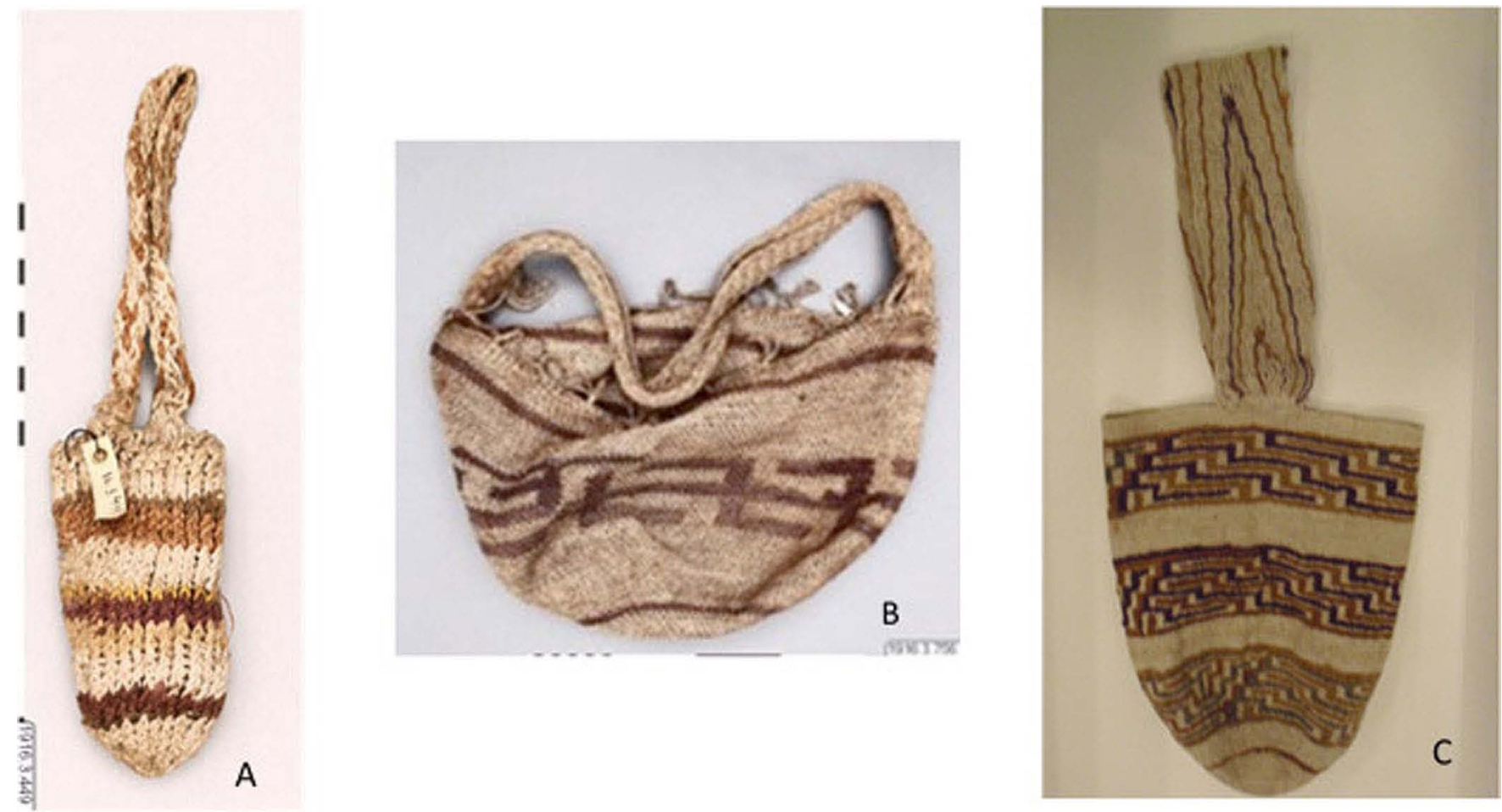

Figura 4. Mochilas Ika, Världskulturmuseet, Gotemburgo, Suecia A. Mochila de algodón 1916.03.0449, 28 cm, utilizada para guardar el hayo. B. Mochila de fique 1916.03.7056, $73 \mathrm{~cm}$, utilizada para transportar y almacenar los productos de intercambio y regalo. C. Mochila de algodón, $60 \mathrm{~cm}, 1916.03 .0433$, utilizada para guardar y transportar objetos personales.

y diecisiete en lana, con diferente tamaño. Los motivos de las mochilas en algodón y fique al igual que en las mantas, pantalones y otros objetos tejidos están hechos con fibras teñidas. Los motivos en las mochilas de lana en la mayoría de los casos fueron hechos con los diferentes colores naturales de la lana, estas son las mochilas más comercializadas en la actualidad.

La revisión de la información sobre las diferentes mochilas de la colección y la consulta con miembros de la comunidad Ika, permite observar que existe una relación entre la forma y los materiales con los que fueron elaboradas con su uso. Como se puede apreciar en la Figura (4), con tres ejemplos, en A) la mochila de algodón 1916.3.449, de $28 \mathrm{~cm}$ de largo, es utilizada para guardar el hayo (hojas secas de coca), en B) la mochila de fique $1916.3 .756 \mathrm{de} 73 \mathrm{~cm}$ de largo, es utilizada para transportar y almacenar los productos de intercambio y regalo y en C) la mochila de algodón, 1916.3.433, de $60 \mathrm{~cm}$ es utilizada para guardar y transportar objetos personales, entre estos la mochila que contiene el hayo.

Además de la colección de objetos materiales, en la base de datos del museo se encuentra el registro fotográfico de la permanencia de Gustav Bolinder en Nabusimake, que muestra la importancia del uso de las mochilas en la vida cotidiana de los Ika (Figura 5). Este material está a disposición del público a través de la página web del museo: http://collections.smvk.se/carlotta-vkm/web.

Para establecer la relación entre los diferentes objetos de la colección y las especies colorantes de uso actual por la comunidad, se desarrolló una metodología que consistió en hacer la toma de muestras de un grupo de mochilas seleccionadas en la colección Bolinder, establecer la correspondencia entre el nombre común de las plantas de la colección y el nombre en Ika de las especies de uso tradicional, ya identificadas. Asignar el nombre científico a las plantas utilizadas en las muestras etnográficas teñidas. Finalmente, realizar el análisis químico para buscar identificar las fuentes de colorantes presentes en las muestras etnográficas.

\section{Metodología}

\section{Actividades desarrolladas en el Museo etnográfico.}

1.1. Toma de muestras de un grupo de mochilas seleccionadas. La toma de muestras se realizó en enero del año 2015 en las instalaciones del museo etnográfico, de acuerdo a la disponibilidad y al estilo del material.

1.2. Relación entre el nombre común de las plantas de la colección y el nombre en Ika de las especies de uso 


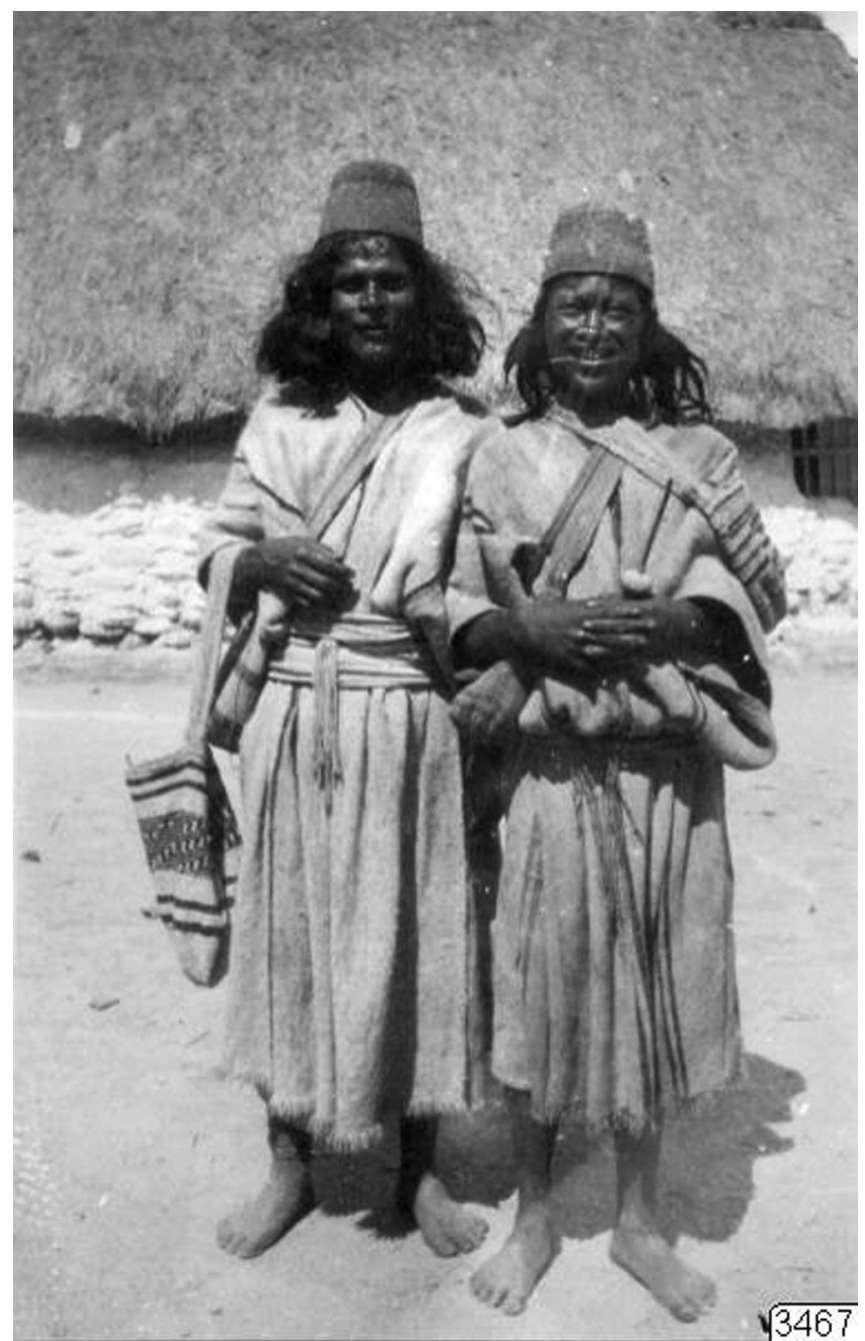

Figura 5. Jovenes Ika en Nabusimake, fotografía tomada del archivo de Gustav Bolinder (oo3467).

tradicional ya identificadas. Debido a que los nombres Ika de las plantas de la colección están transcritos a ortografía sueca la relación con el nombre Ika se hizo inicialmente por semejanza en la escritura y por la muestra de la planta, si esta se encontraba en la colección. Por ejemplo, para el nombre de la ficha original 1916.03.070o Sikkara, esta corresponde a una fibra teñida con Sikara y para 1916.03.0651 Orh, esta corresponde a una fibra teñida con Uru que a la vez tiene la muestra de la planta 1916.03.0778, ver Tabla (2).

1.3. Correspondencia entre el nombre común y el nombre científico de las plantas utilizadas en las muestras etnográficas teñidas. Esta se realizó con la información disponible sobre las especies tintóreas de uso tradicional identificadas previamente (Devia et al. 2016) y en algunos casos por las muestras de las plantas presentes en la colección.

\section{Actividades desarrolladas con la comunidad.}

Actividades desarrolladas con la comunidad, corresponden a la información sobre las especies colorantes y el teñido de uso actual, desarrollada durante el proyecto ${ }^{3}$.

\section{Trabajo de laboratorio}

Para el análisis de los colorantes presentes en materiales etnográficos se siguen los métodos desarrollados para el estudio de los colorantes en materiales arqueológicos, que involucran la preparación del material de referencia y la selección de sistemas de extracción y análisis (Devia y Cardale de Schrimpff 2017). En este caso el material de referencia esta formado por las muestras preparadas con las plantas tintóreas.

3.1. Preparación de muestras con las plantas tintóreas. Para determinar los compuestos colorantes en las especies tintóreas se prepararon muestras teñidas con estas especies sobre algodón y fique, variando algunos parámetros como temperatura en las que se considero $20^{\circ} \mathrm{C}$ como temperatura ambiente y $92^{\circ} \mathrm{C}$ la temperatura de ebullición a $560 \mathrm{mmHg}$ de presion, con teñido directo (sin mordiente) y con alumbre como mordiente. Se determinaron las condiciones óptimas de teñido y se tomaron las muestras para el análisis.

3.2. Identificación de los colorantes presentes en las especies tintóreas. La extracción de los colorantes de las muestras teñidas se realizó mediante hidrólisis suave con ácido oxálico, una adaptación del método de Guinot (2006). La composición en moléculas colorantes fue analizada por cromatografía líquida con el empleo de un detector de arreglo de diodos, HPLC-DAD con una base de datos de compuestos puros colorantes. Tomando como criterio de identificación la correspondencia con el tiempo de retención y espectro UV-VIS (Devia y Cardale de Schrimpff, 2017).

En el caso en que no se conocía la química de los extractos colorantes de algunas de las especies tintóreas, se siguieron los métodos de extracción, separación y aislamiento de la fitoquímica convencional y de la química instrumental para la identificación y elucidación de estructuras. Luego se procedió a

3. "Contribución al conocimiento de las fuentes de colorantes precolombinos a partir del estudio de las especies colorantes de uso tradicional por la comunidad indígena Ika de Nabusímake, Sierra Nevada de Santa Marta, Colombia. Terminado en el año 2015. 


\begin{tabular}{|c|c|c|c|c|}
\hline \multicolumn{2}{|c|}{ Especie } & \multicolumn{2}{|c|}{ Muestra teñida (ficha /nombre) } & \multirow{2}{*}{\begin{tabular}{|l}
$\begin{array}{c}\text { Muestra de la } \\
\text { planta tintórea }\end{array}$ \\
Ficha o código
\end{tabular}} \\
\hline Nombre científico & Nombre Ika & Algodón & Fique & \\
\hline Picramnia gracilis Tul. & Urú & 1916.03.0651 Orh & $\begin{array}{l}1916.03 .0694^{\mathrm{a}} \\
\text { Orh }\end{array}$ & 1916.03.0778 \\
\hline Weinmannia pinnata $\mathrm{L}$. & Kuwigne & $\begin{array}{l}\text { 1916.03.0652 } \\
\text { Kogoina }\end{array}$ & & 1916.03.0780 \\
\hline Chaetolepis alpina Naudin & Uchaba & $\begin{array}{l}\text { 1916.03.0653 } \\
\text { Otjava }\end{array}$ & - & 1916.03.0779 \\
\hline Mucuna sp. & Sikura & $\begin{array}{l}\text { 1916.03.0654 } \\
\text { Sikkará }\end{array}$ & $\begin{array}{l}\text { 1916.03.0694b } \\
\text { Sikkara }\end{array}$ & \\
\hline $\begin{array}{l}\text { Fridericia chica (Bonpl.) L.G. } \\
\text { Lohmann }\end{array}$ & Sisita & $\begin{array}{l}\text { 1916.03.0698 } \\
\text { Sisita }\end{array}$ & & \\
\hline Curcuma longa L. & Batatilla & $\begin{array}{l}\text { 1916.03.0650 } \\
\text { Batatilla }\end{array}$ & - & - \\
\hline Myrsine coriaceae $S w$. & Yeganu & $\begin{array}{l}\text { 1916.03.0655 } \\
\text { Tjannung }\end{array}$ & $\begin{array}{l}\text { 1916.03.0693 } \\
\text { Tjannung }\end{array}$ & - \\
\hline
\end{tabular}

Tabla 2. Muestras de fibras y plantas de la colección Gustav Bolinder

determinar la presencia de las moléculas colorantes identificadas en las fibras teñidas, como en el caso de Picramnia gracilis nombre común Uru (Devia et al., 2019).

3.3. Análisis de muestras etnográficas. Se siguió un procedimiento de extracción y análisis de colorantes similar al de las muestras teñidas con las plantas tintóreas.

\section{Resultados}

\section{Muestras de mochilas etnográficas.}

Se seleccionó un grupo de diez mochilas y una manta, para un total de dieciseis muestras,con un peso entre 0,2 y $0,5 \mathrm{mg}$.

\section{Muestras de fibras y plantas.}

En la Tabla (2) se observa la correspondencia entre el nombre asignado a las muestras de la colección Bolinder, el nombre Ika actual y el nombre científico de las especies para un grupo de siete especies que son: Picramnia gracilis (Uru), con muestras teñidas sobre algodón y fique, y una muestra de la planta; Weinmannia pinnata (Kugwine) y Chaetolepis alpina (Uchaba), una muestra sobre algodón y una de la planta; Mucuna sp. (Sikura) y Myrcine coriacea (Yeganu) fibras teñidas sobre algodón y fique; Fridericia chica (Sisita) y Curcuma longa (Batatilla) fibras teñidas sobre algodón. Se puede considerar como un indicio de la importancia del teñido sobre algodón en ese momento ${ }^{4}$ el hecho de que se tengan muestras de algodón teñido con las siete especies consideradas.

Es importante anotar que en la base de datos del museo se encuentra la muestra 1916.03.0780 que contiene hojas de Weinmannia pinnata y la muestra 1916.03.0779 con ramas de Chaetolepis alpina, con los nombres de las especies cruzados en sus fichas de identificación. También hay muestras de una planta con el No. de inventario 1916.03.0670 con el nombre de Dinga, descrito como un tinte de color violeta, que aparece en la lista de especies tintóreas en Cardalle de Schrimpff (1972). Fuente de colorantes que hasta el momento no ha sido identificada.

\section{Identificación de los compuestos colorantes presen- tes en las especies tintóreas.}

En la Tabla (3) se observa el resultado del análisis de las fibras de algodón teñidas, con el empleo de la cromatografía 


\begin{tabular}{|l|l|l|}
\hline Nombre científico & Nombre Ika & $\begin{array}{l}\text { Principales compuestos recuperados de las fibras } \\
\text { teñidas y analizados por HPLC-DAD }\end{array}$ \\
\hline Berberis meollacensis & Chunnu & Berberina, jatroricina, barbamina, sanguinarina \\
\hline Bixa orellana & Achote & Bixina y norbixina \\
\hline Bocconia frutescens & Sorkwanu & Sanguinarina y quercetina \\
\hline Chaetolepis alpina & Uchaba & Apigenina y derivados \\
\hline Escallonia paniculata & Manuzitinu & Ácido elágico, quercetina y derivados, kaemferol \\
\hline Fridericia chica & Sisita & Carajurina, arrabidina, 3' hidroxiarrabidina, luteolina, \\
\hline Galium hypocarpium & apigenina, feoforbinde y carotenos \\
\hline Haematoxylum brasiletto & Barrasin & Brasileina y orh \\
\hline Maclura tinctórea & Morita & Morina, maclurina y kaemferol \\
\hline Mucuna sp. & Sikura & Ácido elágico y catequina \\
\hline Myrsine coriacea & Yeganu & Miricetina, kaemferol y cianidina \\
\hline Picramnia gracilis & Uru & Nat-aloeemodina y crisofanol \\
\hline Piper aduncum & Gungunu & Ácido elágico \\
\hline Senna pendula & Jumisai & Ácido elágico y quercetina \\
\hline Weinmannia pinnata & Kugwinu & Ácido elágico y ácido dihidroxibenzoico \\
\hline
\end{tabular}

Tabla 3. Resultado del análisis por HPLC-DAD de los extractos tintóreos obtenidos de especies de uso tradicional por los indígenas Ika de la Sierra Nevada de Santa Marta.

HPLC-DAD, en el laboratorio de colorantes naturales de la Universidad Distrital, Colombia. Para especies como Berberis meollacensis, Bixa orellana, Bocconia frutescens, Fridericia chica, Galium hypocarpium, Maclura tinctórea, Myrsine coriaceae y Picranmia gracilis, la presencia de componentes específicos se puede considerar como marcadores quimiotaxonómicos que evidencian el uso de estas especies en los resultados del análisis químico de muestras de fibras teñidas de materiales etnográficos, históricos y arqueológicos. La presencia de brasileina y el componente orh, se pueden atribuir en general al empleo de especies denominadas "palo brasil" (Nowik, 2001), pero solo considerando otros aspectos como procedencia de las muestras, se podría atribuir exclusivamente al empleo de Haematoxylum brasiletto. Piper aduncun, Mucuna sp., Senna pendula, Weinmannia pinnata y Escallonia paniculata (Torres, 1983) tienen en común el ácido elágico, compuesto que pertenece a los taninos hidrolizables y es frecuente en los extractos vegetales. Como los taninos sirven de mordientes es usual encontrarlo en el análisis de colorantes. Senna pendula y Scallonia paniculata tienen además la quercetina, un flavonol de amplia distribución en la parte aérea de las plantas, en este caso para diferenciar el empleo en el teñido de estas dos especies, se podría utilizar como criterio la determinación de kaemferol y los porcentajes en la composición.

\section{Análisis de los extractos colorantes de Picramnia gracilis}

De la fitoquímica de esta especie se conocía muy poco cuando se abordó la investigación sobre las especies colorantes utilizadas por los indígenas Ika y, considerando que es una de las especies más apreciadas en el teñido tradicional, se realizó una investigación paralela con el fin de determinar sus principales moléculas colorantes.

Picramnia gracilis Tul, Picramniaceae. Sin. Picramnia dwyeri D.M Porter y Picramnia monninifolia Rusby. Nombre común: Pakaburwi (Panamá); Uru (Ika, Colombia). (Figura 6)

Nativa del continente americano, está presente en bosques húmedos, en la región tropical del norte del Ecuador, con distribución en Centro América, Panamá y Costa Rica y en el norte de Suramérica Ecuador, Venezuela y Colombia. Se encuentra en la Sierra Nevada de Santa Marta, como también en las montañas de los Andes colombianos en la Cordillera Central. Investigaciones en Colombia han mostrado una fuerte acción contra la leshmaniosis de una flavona aislada de los frutos de la especie (Robledo et al 2015). Otras especies del mismo género son utilizadas como colorantes en el Trapecio Amazónico (Klinger 1998) y en Perú y Ecuador (Riveros y Inga 2014).

Picramnia gracilis es un árbol con hojas verdes que una vez secas se vuelven rojizas, las cuales son ampliamente 


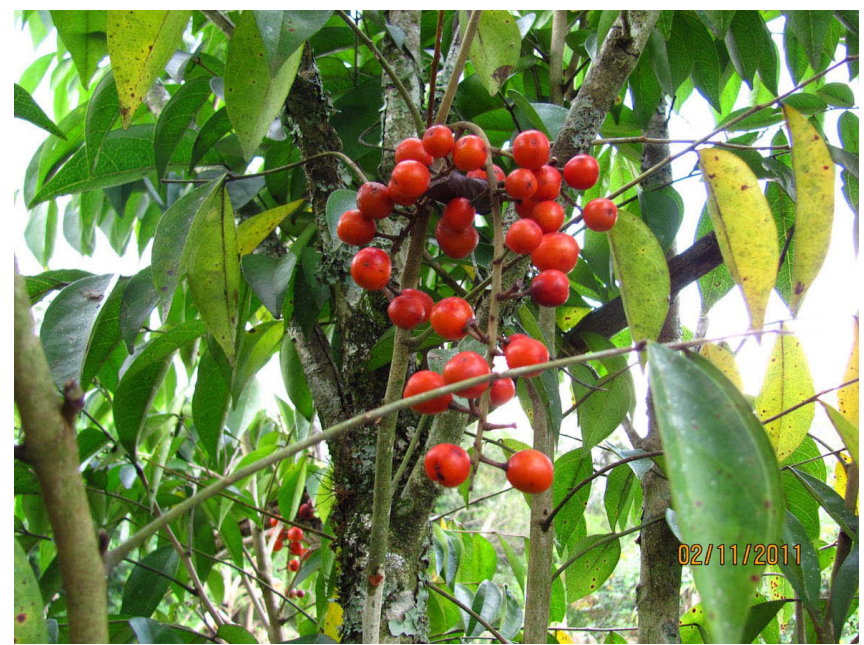

Figura 6. Picramnia gracilis Tul. (Uru) con frutos, árbol de aproximadamente 5 m. Fotografía tomada por Ricardo Niño Izquierdo.

utilizadas para el teñido en tonos rojos y violetas. El análisis del extracto etanólico de las hojas de Picramnia gracilis por HPLC-DAD indicó la presencia de crisofanol, emodina, aloemodina y nataloemodina. La partición liquido-liquido de este extracto con solventes de diferente polaridad y, separación por cromatográfia de columna utilizando Silica gel H (6o Mesh) y Sephadex LH-2o permitió el aislamiento y elucidación por RMN ${ }^{1} \mathrm{H} \mathrm{y}{ }^{13} \mathrm{C}$, FTIR, EM de nataloemodina y crisofanol. Compuestos que junto con emodina y aloemodina se reportan por primera vez para la especie (Devia et al 2019).

La Figura (7) muestra el perfil cromatográfico, por HPLCDAD, del extracto etanólico y sus principales componentes. Los resultados indican la presencia de antraquinonas como aloemodina, nataloemodina, emodina y crisofanol. En el cromatograma A, se observa la nataloemodina como el principal componente. El cromatograma de la parte inferior muestra a nataloemodina y crisofanol como los componentes obtenidos en el extracto tintóreo de las fibras de algodón mordentadas y teñidas a $20^{\circ} \mathrm{C}$, como se describe más adelante en la parte correspondiente a las mejores condiciones para el teñido.

\section{Teñido con Picramnia gracilis}

Se sumergió un textil de algodón mordentado con alumbre (sal doble de Aluminio y Potasio) en una solución preparada con hojas frescas y molidas en una proporción 1:3, tres

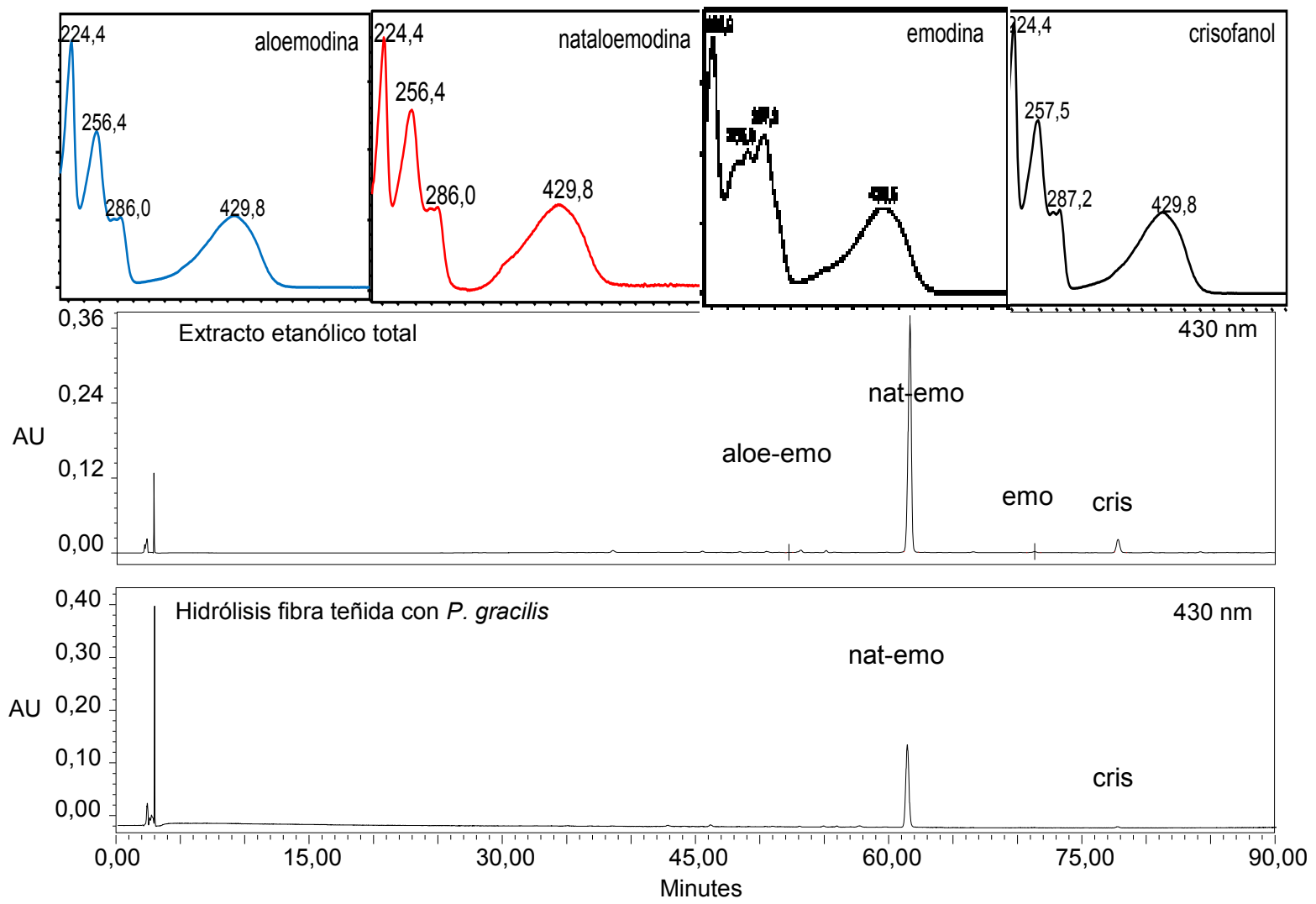

Figura 7. Análisis por cromatografía HPLC-DAD del extracto etanólico de hojas de Picramnia gracilis y del extracto tintóreo de fibras teñidas con las hojas de Picramnia gracilis. Cromatogramas a $430 \mathrm{~nm}$ y espectros ultravioleta-visible, UV-VIS. Aloe-emo: Aloemodina, nat-emo: nataloemodina, emo: emodina, cris: crisofanol. 

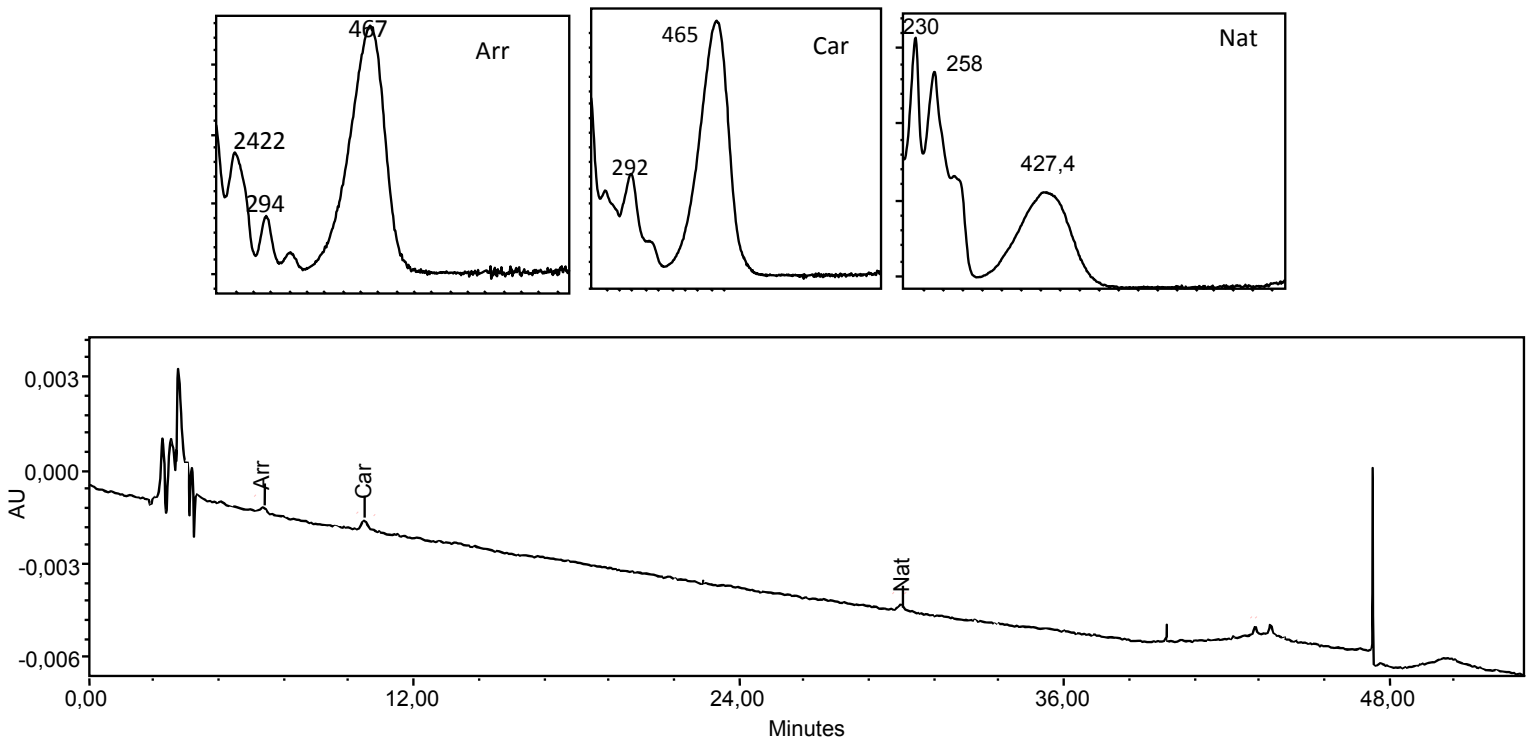

Figura 8. Cromatograma a $470 \mathrm{~nm}$ y espectros UV-VIS tomados de la muestra TE1916 .03.499, fibras marrón. Arr: Arrabidina, Car: Carajurina, Nat: Nataloemodina

veces el peso de las hojas respecto a una vez el peso de las fibras, durante 12 horas a a $20^{\circ} \mathrm{C}$. Se retiró el textil teñido y se lavó con abundante agua, hasta observar las aguas de lavado incoloras y se secó a la sombra. El resultado obtenido se observa en la tabla 1.

\section{Análisis del material etnográfico.}

En la tabla (4) se encuentra el registro de los objetos textiles analizados por código, el color y número de muestras tomadas, la clase de fibra, los compuestos colorantes determinados y la posible fuente de estos colorantes. Se tomaron muestras de fibras coloreadas de diez mochilas y de los hilos coloreados de una manta para un total de 16 muestras.

El material etnográfico se analizó con el mismo método y bajo las mismas condiciones que el material de referencia. En la Figura (8), se muestra el resultado del análisis por HPLC-DAD de las fibras coloreadas tomadas de la mochila TE 1916.03.499. Los resultados indican en las fibras marrón la presencia de: Fridericia chica (Sisita) y Picramnia gracilis (Uru). La identificación de F. chica se hizo de acuerdo a los espectros UV-VIS y los tiempos de retención de sus principales componentes descritos en (Devia et al. 2017). En la Figura (9), se observa el resultado del análisis de las fibras marrón de la mochila TE 1916.03.433 (Figura 4, C). En este caso la identificación del espectro UV-Vis de Orh, conocido como un producto de degradación en el teñido con especies de palo brasil, (Nowik, 2001), evidencia el empleo de una de estas especies. La presencia del ácido elágico se considera como indicio del uso de fuentes de taninos, posiblemente empleadas como mordiente durante el proceso de teñido.

En las fibras marrón de la muestra 1916.03.786 (Figura 10), se determinó indigo al lado de un colorante azul sintético. Es interesante observar el empleo del azul en los colorantes Ika de esta colección, porque en la actualidad no se dispone de información etnográfica sobre el empleo de fuentes de este color. Los tonos más similares a los logrados con el índigo son los grises oscuros que proporciona Mucuna sp. (Sikura) (Barranco Perez, 2010 ). Por lo que es muy posible que se trate de índigo sintético porque no se observan otras absorciones características del empleo de una indigófera como es el caso de la Indirubina en los materiales arqueológicos (Devia y Cardale de Schrimpff, 2017).

En las muestras color marrón de las mochilas en fibra de lana 1916.03.421 ( Figura 11C) y 1916.03.425, con diseños sobre fondo blanco la primera y habano la segunda, no se detectarón colorantes, por lo que el color observado muy posiblemente corresponde a al color natural de la lana, utilizada para reemplazar las fibras teñidas en los diseños.

De la mochila en algodón 1916.03.423 (Figura 11A) se tomó dos muestras de los diseños de lineas paralelas horizontales coloreadas sobre fondo blanco. En la muestra color purpúra se evidenció el empleo de Picramnia gracilis por la presencia de nataloemodina y de una fuente de taninos por el ácido elágico. En la muestra rosada los perfiles de los espectros UV-VIS observados son similares pero no iguales a diferentes categorias de colorantes sintéticos (de Keyser, 2017). 


\begin{tabular}{|c|c|c|c|c|}
\hline Código & Color de la muestra* & Fibra & Resultados & Fuente de colorantes \\
\hline $1916.03 \cdot 421$ & Marrón & Lana & No se detectaron colorantes & No se detectaron colorantes \\
\hline \multirow{2}{*}{1916.03 .423} & Púrpura & \multirow{2}{*}{ Algodón } & Nataloemodina y ácido elágico & $\begin{array}{l}\text { Picrammia gracilis y fuente } \\
\text { de taninos }\end{array}$ \\
\hline & Rosado & & $\begin{array}{l}\text { Colorantentes sintéticos no } \\
\text { identificados }\end{array}$ & $\begin{array}{l}\text { Colorantes sintéticos no } \\
\text { identificados }\end{array}$ \\
\hline 1916.03 .425 & Marrón & Lana & No se detectaron colorantes & No se detectaron colorantes \\
\hline 1916.03 .433 & Marrón & Algodón & $\begin{array}{l}\text { Brasileina, ácido elágico y } \\
\text { colorantes sin identificar }\end{array}$ & Palo brasil y fuente de taninos \\
\hline 1916.03 .499 & Marrón & Algodón & $\begin{array}{l}\text { Arrabidina, Carajurina, } \\
\text { Nataloemidona }\end{array}$ & $\begin{array}{l}\text { Fridericia chica y } \\
\text { Picramnia gracilis }\end{array}$ \\
\hline \multirow{3}{*}{1916.03 .685} & Marrón & \multirow{3}{*}{ Algodón } & $\begin{array}{l}\text { Nataloemodina y una quinona } \\
\text { desconocida }\end{array}$ & Picramnia gracilis \\
\hline & Rojo & & $\begin{array}{l}\text { Colorantes con UV-VIS similar } \\
\text { al de los antocianos }\end{array}$ & Colorantes sin idenificar \\
\hline & Habano & & Berberina, carajurina y brasileina & $\begin{array}{l}\text { Berberis meollacensis, } \\
\text { Fridericia chica y palo brasil }\end{array}$ \\
\hline 1916.03 .756 & Marrón & Fique & Nataloemodina & Picramnia gracilis \\
\hline \multirow{3}{*}{$1916.03 \cdot 758$} & Habano & \multirow{3}{*}{ Fique } & Nataloemodina & Picramnia gracilis \\
\hline & Marrón & & $\begin{array}{l}\text { Nataloemodina y derivados } \\
\text { de la apigenina }\end{array}$ & $\begin{array}{l}\text { Picramnia gracilis y derivados } \\
\text { de la apigenina }\end{array}$ \\
\hline & Amarillo & & Berberina y ácido elágico & $\begin{array}{l}\text { Berberis meollacensis y fuente } \\
\text { de taninos }\end{array}$ \\
\hline 16.03 .786 & Blanco-Amarillento & Algodón & $\begin{array}{l}\text { Indigotina y colorante } \\
\text { sintético azul }\end{array}$ & Índigo y colorante sintético azul \\
\hline \multirow{2}{*}{$1916.03 \cdot 745$} & Marrón & \multirow{2}{*}{ Algodón } & Ac. elágico y berberina & $\begin{array}{l}\text { Berberis meollacensis y fuente } \\
\text { de taninos }\end{array}$ \\
\hline & Marrón rojizo & & Ac. elágico y berberina & $\begin{array}{l}\text { Berberis meollacensis y fuente } \\
\text { de taninos }\end{array}$ \\
\hline
\end{tabular}

*Muestras tomadas de los diseños de las mochilas, excepto para las muestras de la manta 1916.03.745

Tabla 4. Identificación de colorantes y fuentes de colorantes en las muestras analizadas de la colección Gustav Bolinder.

P. gracilis está presente, como ya se discutió, en las fibras de algodón marrón de la muestra 1916.03.499 y en las del mismo color en fique de la muestra 1916.03.756 (Figura 4B) y en la muestra color habano 1916.03.758. (Figura 11B). La combinación de los colorantes de esta especie con otras fuentes de colorantes se pueden observar en la muestra de algodón marrón 1916.03.499, donde la presencia de las deoxiantocianidinas arrabidina y carajurina son indicios de una mezcla con los colorantes provenientes de Fridericia chica y en el caso de las fibras en fique color marrón 


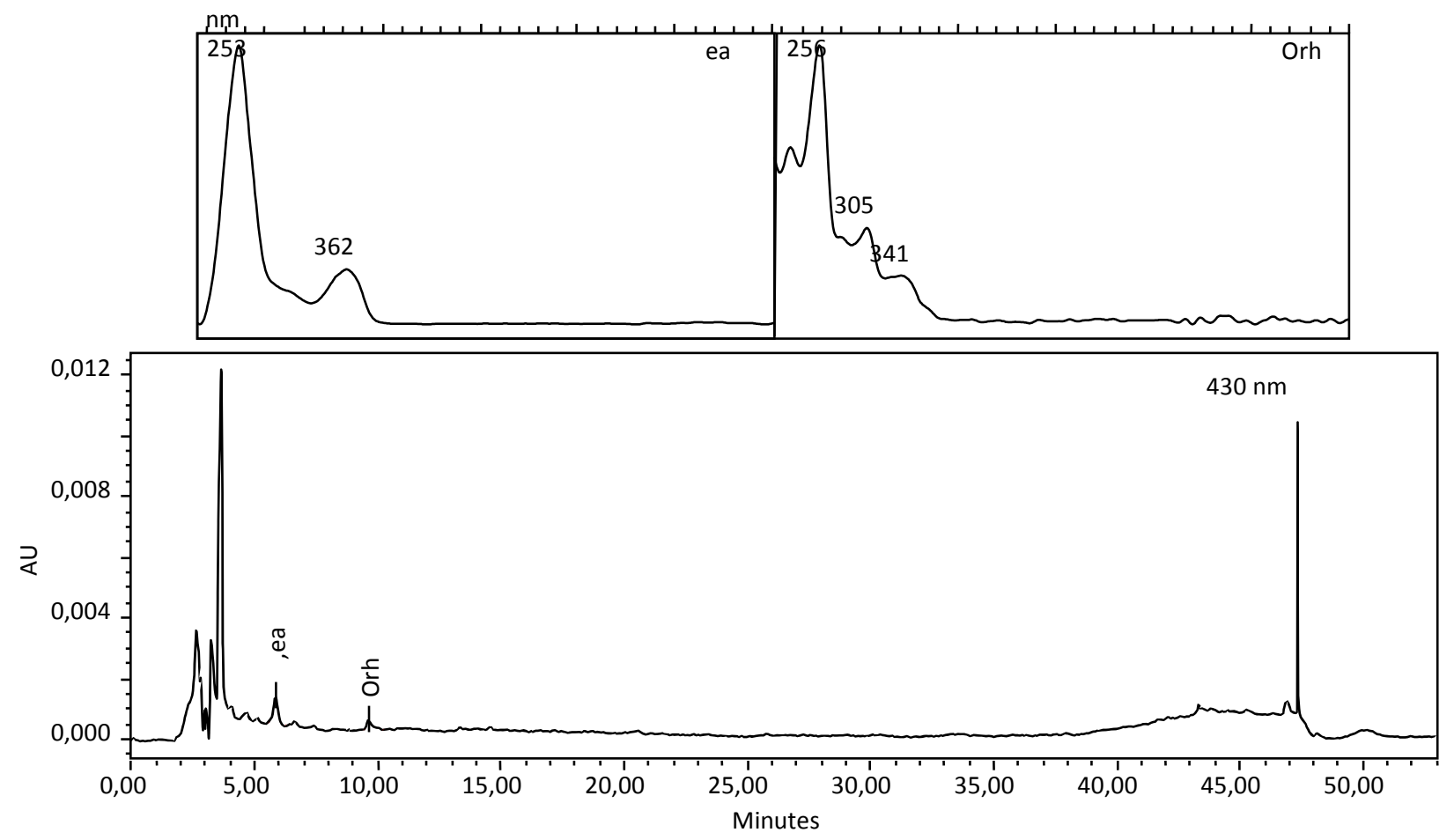

Figura 9. Cromatograma a $430 \mathrm{~nm}$ y espectros UV-VIS tomados de la muestra TE 1916 .03.433, fibras marrón. Orh: producto de degradación en el teñido con especies de palo brasil, ea: ácido elágico.

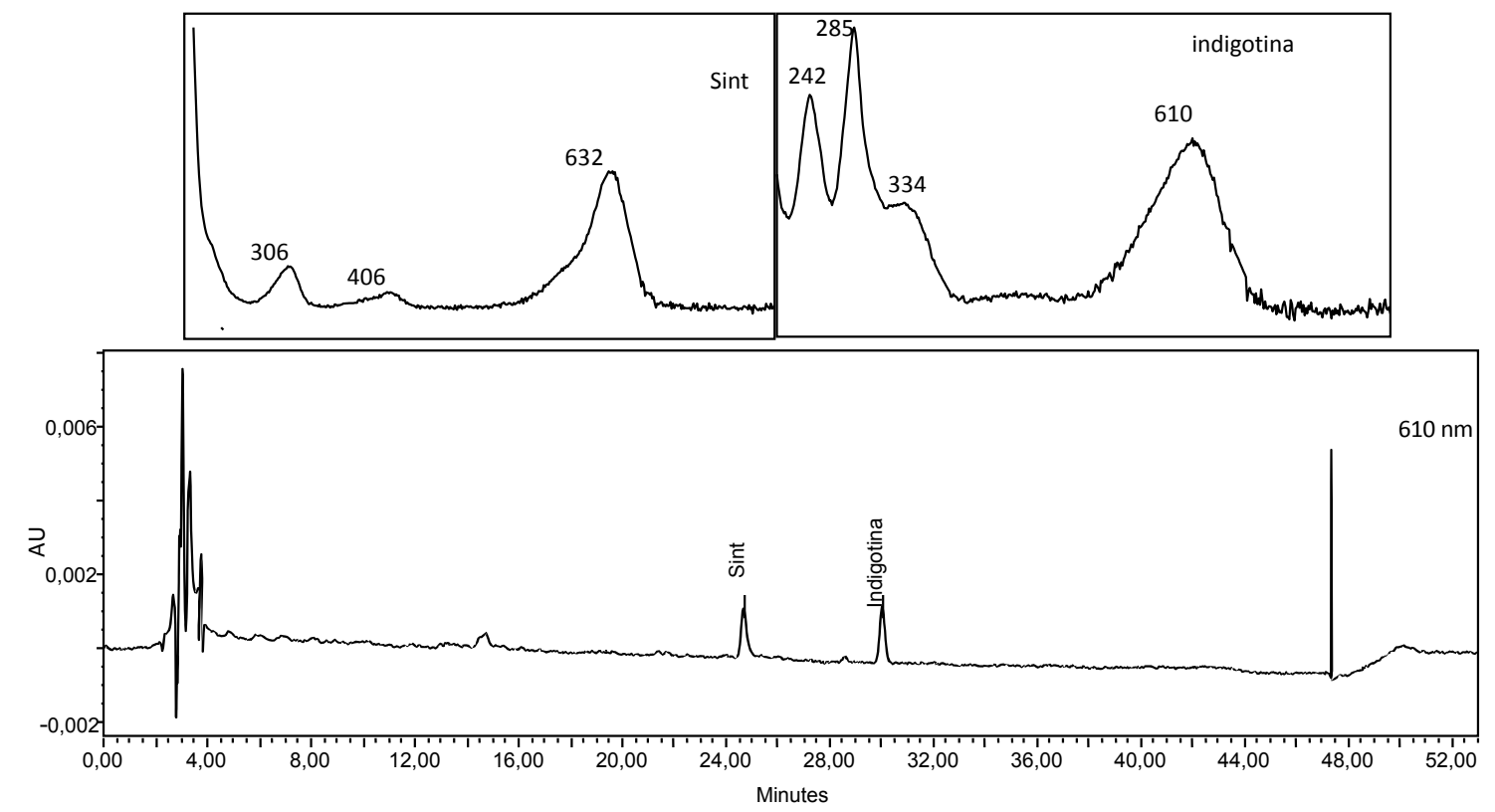

Figura 10. Cromatograma a $610 \mathrm{~nm}$ y espectros UV-VIS tomados de la muestra TE 1916 .03.786, fibras marrón. Sint: colorante sintético sin identificar. Indigotina: Indigotina. 

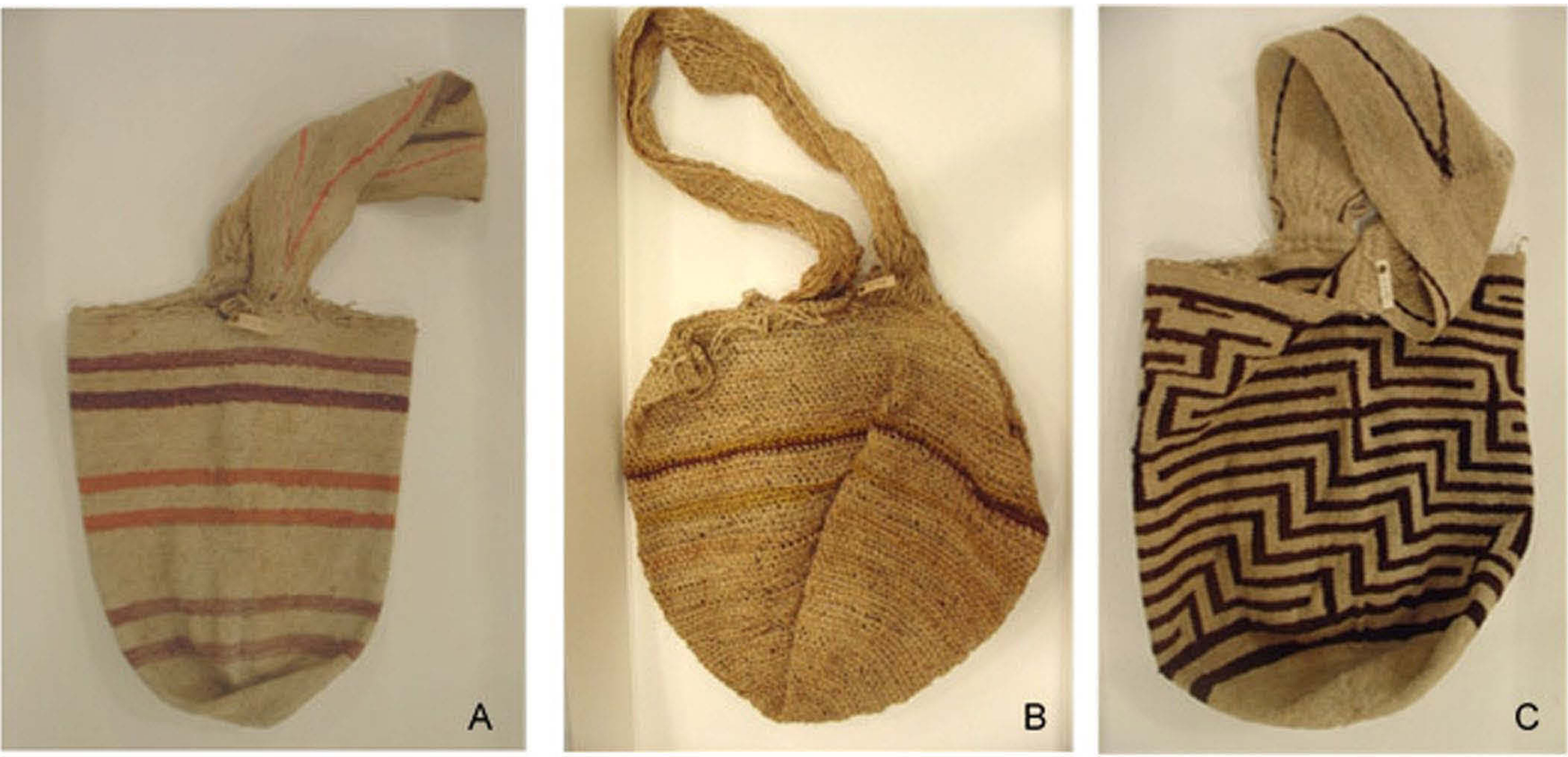

Figura 11. Mochilas Ika, Världskulturmuseet, Gotemburgo, Suecia, A) En la muestra de algodón color purpúra 1916.03.423, se determinó Picramnia gracilis con una fuente de taninos y en la muestra de algodón rosada posiblemente colorantes sintéticos. B) En las fibras de fique amarillas 1916.03.758 se determinó Berberis meollacensis C) En la mochila en lana 1916.03.421, los diseños fueron realizados con el color de la lana natural.

1916.03.758, por la presencia de derivados de la apigenina de una fuente de flavonas como Chaetolepis alpina.

Otras mezclas de fuentes de colorantes se pueden observar entre Fridericia chica, Berberis meollacensis y palo brasil en la muestra en algodón color habano 1916.03.685. El palo brasil también se observa con una fuente de taninos en la muestra de algodón marrón 1916.03.433, en el cromatograma de la (Figura 9). La atribución de Berberis meollacensis en tres de las muestras estudiadas, algodón color habano 1916.03.685, fique amarillo 1916.03.758 y algodón marrón y marrón rojizo en 1916.03.499, se hizo por la determinación en el análisis de la Berberina, alcaloide característico de ese género de plantas (Manosalva et al. 2014).El género Berberis de amplia distribución en las regiones tropicales y en el sur de Europa y Asía, se conoce por el empleo de sus especies como plantas ornamentales, por sus propiedades medicinales y en algunas regiones del mundo como fuentes de colorantes amarillos (Zhang et al. 2010). En Colombia existe cerca de 45 especies, entre las cuales Berberis meollacensis es considerada endémica de la Sierra Nevada de Santa Marta (Camargo1981).

Algunas caracteríscas que se manifiestan en los procedimientos de teñido es el empleo de sustancias tánicas al lado de los colorantes de Picramnia gracilis y Berberis meollacensis. El empleo de mezclas de diferentes fuentes de colorantes para la obtención de un determinado color en las fibras y el uso de fuentes naturales conocidas al lado de posibles fuentes naturales desconocidas como en la muestra 191603.685. Empleo de fibras teñidas con colorantes naturales y de posibles colorantes sintéticos para la elaboración de los diseños, muestra 1916.03.433 de la figura (4C).

\section{Observaciones finales}

En las mochilas ika de la colección etnográfica realizada por Gustav Bolinder se pudo determinar el empleo de fuentes de colorantes vegetales.

Entre las fuentes de colorantes vegetales se encuentra: Picramnia gracilis, Fredericia chica, Berberis meollacensis, especies de palo brasil y de taninos. Picramnia gracilis fue la especie determinada en un grupo mayor de muestras y presenta además en la colección evidencias de su empleo en una muestra de la planta y en fibras de algodón y fique teñidas. Las fuentes de taninos en el teñido pueden ser Weinmannia pinnata, que tiene en la colección muestras de algodón teñidas y de la planta y Mucuna sp. para la que también existe fibras de algodón teñidas en la colección. Fredericia chica y especies de palo brasil son fuentes de colorantes comunes con los colorantes prehispánicos.

En la colección de Gustav Bolinder se puede apreciar la influencia de la misión de los capuchinos, en la sustitución de los materiales y técnicas ancestrales para la elaboración 
de las mochilas, como ha sido el uso de las fibras de lana por las de algodón y la elaboración de los motivos con fibras del color natural de la lana, disminuyendo el teñido del algodón. Se observa también evidencias del empleo de colorantes sintéticos. Es importante iniciar el estudio sistemático de los colorantes sintéticos, que puede proporcionar información sobre su introducción en el país.

La lista de las especies tintóreas utilizadas por la comunidad Ika de Nabusimake pasará a ampliar la lista del material de referencia para el estudio de los colorantes en los textiles prehispánicos Los objetos de esta colección contienen información valiosa sobre otras fuentes de colorantes naturales que se debe continuar investigando y sobre el uso de los colorantes sintéticos y su introducción en el país.

\section{Agradecimientos}

Asociación de mujeres Ika, Akitinkuchua, Nabusimake, Pueblo Bello, (Cesar).

Camilo Niño, écologo, mienbro de la communidad Ika.

Estudiantes del grupo Colorantes Naturales de la carrera de Licenciatura en Química de la Universidad Distrital Francisco José de Caldas, Bogotá, Colombia.

Carlos Devia, asesor en el proyecto realizado con la comunidad IKA, profesor -investigador de la Universidad Javeriana.

Jan Amnehall, centro de documentación del Världskulturmuseet en Gotemburgo.

Adriana Muñoz, curadora del Världskulturmuseet en Gotemburgo.

Manuela Fischer, curadora, Museo Etnológico, Berlín.

Fundación de investigaciones Arqueológicas, FIAN, cofinanciadora del proyecto

\section{Referencias citadas}

Aroca Araújo, Armando.

2009 Una propuesta de enseñanza de geometría desde una perspectiva cultural. Caso de estudio: Comunidad Indígena Ika - Sierra Nevada de Santa Marta. Universidad del Valle, instituto de educación y pedagogía, Santiago de Cali.

Barranco Pérez, Wilmar.

2010 Especies vegetales de uso antiofídico en las estribaciones de la Sierra Nevada de Santa Marta: inventario etnobotánica y evaluación biológica. Tesis de maestría. Facultad de Ciencias Agrarias. Universidad Nacional de Colombia, sede Medellín.
Bolinder, Gustaf.

1925 Die Indianer der tropischen Schneegebirge: Forschungen im nordlichsten Sudamerika. Editorial: Strecker \& Schroder, Stuttgart.

Camargo, Luis A.

1981 Especies nuevas del género Berberis. Caldasia. 13, 62, 203-223.

Cardale de Schrimpff, Marianne.

1972 Techniques of hand-weaving and allied arts in Colombia (with particular reference to indigenous methods and, where possible, including dyeing, fibre preparation and related subjects). I: 205-214. University Microfilms International.

de Keijser, Mathijs and Maarten R. van Bommel.

2017 New colours: the history and analysis of fluorescein, eosin, erythrosine, rodhamine and some of their derivatives. The diversity of Dyes in History and Archaeology Edited by Jo Kirby Archetype Publications Ltda, pp. 326-338. London.

Devia, Beatriz, Marianne Cardale de Schrimpff, Carlos Devia y

Camilo Niño Izquierdo.

2016 Aproximación al conocimiento de los colorantes en la comunidad indígena ika de la Sierra Nevada de Santa Marta (departamento del Cesar, Colombia). Nuevo mundo Mundos Nuevos. https://journals. openedition.org/nuevomundo/69205 consultado el 10 de agosto 2019 .

Devia, Beatriz y Marianne Cardale de Schrimpff.

2017 Los textiles precolombinos de Nariño y del Ecuador: similitudes y diferencias en colorantes, técnicas $y$ diseños. Cuestiones \& Diálogos, 1. Instituto Colombiano de Antropología e Historia. Bogotá.

Devia, Beatriz, Marianne Cardale de Schrimpff, Monique Tits and Jan Wouters.

2017 Arrabidaea chica: 3-deoxyanthocyanidins and their degradation products found in Colombian archaeological textiles of the 1oth-17 th centuries. The diversity of Dyes in History and Archaeology Edited by Jo Kirby Archetype Publications Ltd, pp. 54-68. London.

Devia Castillo Beatriz, Oscar J. Yepez, Mónica A. Rey, Diego A. Silva.

2019 Primer reporte de antraquinonas en hojas de Picramnia gracilis Tul. Revista Cubana de Química. 31:3 Santiago de Cuba sept.-dic. versión On-line ISSN 2224-5421.

Freire-González, Rosa y Marlén Vistel-Vigo

2015 Caracterización fitoquímica de la Curcuma longa L. Rev. Cubana Quím. 27(1): 9-18. 
Giraldo Jaramillo, Natalia.

2014 Camino en espiral-Yo'sa ingunu: territorio sagrado y autoridades tradicionales en la comunidad indígena Iku (Arhuaco) de la Sierra Nevada de Santa Marta. Colombia. Colección Laurea. Universidad de Caldas. Manizales, Colombia.

Guinot Pauline, Aline Rogé, Annick Gargadennec, Michel García, Daniel Dupont, Edwige Lecoeur, Laurent Candelier y Claude Andary.

2006 Dyeing plants screening: an approach to combine past heritage and present development. Society of Dyes and Colourist, Color. Technol., 122: 93-101.

Klinger, William.

1998 Estudio de las Especies Promisorias Productoras de Colorantes en el Trapecio Amazónico. COLOMBIA Forestal 5 (11): 15-33.

Manosalva Loreto, Ana Mutis, Juan Díaz, Alejandro Úrzua,Victor Fajardo y Andrés Quiroz.

2014 Identification of isoquinoline alkaloids from Berberis microphylla by HPLC ESI-MS/MS. Bol Latinoam Caribe Plant Med Aromat 13 (14): 324-335.

Niño Izquierdo Camilo.

2011 Organización y uso del territorio por la comunidad Indígena Arhuaca de Nabusímake Sierra Nevada de Santa Marta (Colombia). Trabajo inédito.Trabajo de investigación presentado como requisito para optar el título de Ecólogo. Facultad de Estudio Ambientales y Rurales, Pontificia Universidad Javeriana. Bogotá.

Nowik, Witold.

2001 The possibility of differentiation and identification of red and blue 'soluble' dyewoods. Dyes in History and Archaeology 18: 129-144.

Patiño, Victor.

1975-1976 Historia de la Cultura Material en la América Equinoccial. Fondo de Cultura Económica. VI(XIII): 252-255.
Reichel-Dolmatoff, Gerard.

1949-1950 Los Kogi, Revista del Instituto Etnológico Nacional. 1949-1950. I: 259 y II: 87.

Riveros, Luisa y Lylyams Inga.

2014 Caracterización química de los extractos colorantes de siete especies forestales del fijador natural, utilizado en 19 comunidades indígenas de Ucayali, Perú. Ciencia Amazónica (Iquitos). 4(1): 29-36.

Robledo Sara, Wilson Cardona, Karen Ligardo, Jéssica Henao, Natalia Arbeláez, Andres Montoya, Fernando Alzate, Juan Pérez, Victor Arango, Ivan Vélez y Jairo Sáez.

2015 Antileishmanial Effect of 5,3'-Hydroxy-7,4'dimethoxyflavanone of Picramnia gracilis Tul. (Picramniaceae) Fruit: In Vitro and In Vivo Studies, Advances in Pharmacological Sciences 1:1-8.

Torres, Jorge H.

1983 Contribución al conocimiento de las plantas tánicas registradas en Colombia. Bogotá: Instituto de Ciencias Naturales -Museo de Historia Natural, Biblioteca José Jeronimo Triana, No. 3. Universidad Nacional de Colombia - COLCIENCIAS. Bogotá.

Uribe, Carlos.

1990 Nosotros los hermanos mayores: Continuidad y cambio entre los Kaggaba de la Sierra Nevada de Santa Marta. Bogotá Universidad de los Andes.

Zhang, Xian, Chika Mouri, Masayuki Mikage and Richard Laursen.

2010 Preliminary Studies Toward Identification of Sources of Protoberberine Alkaloids used as Yellow Dyes in Asian Objects of Historical Interest. Studies in Conservation 554: 177-185. 